\title{
Efiects of Expanded Human Adipose Tissue-Derived Mesenchymal Stem Cells on the Viability of Cryopreserved Fat Graits in the Nude Mouse
}

\author{
Myung-Soon Ko',2, Ji-Youl Jung², II-Seob Shin'1, Eun-Wha Choi³, Jae-Hoon Kim², Sung Keun Kang', Jeong \\ Chan $\mathrm{Ra}^{1, \bigotimes}$
}

1. Stem Cell Research Center, RNL BIO Co., Ltd, Seoul 153-803, Republic of Korea

2. College of Veterinary Medicine, Jeju National University, Jeju 690-756, Republic of Korea

3. Laboratory Animal Research Center, Samsung Biomedical Research Institute, 50 Irwon-dong Gangnam-gu, Seoul 135-710, Republic of Korea

$\triangle$ Corresponding author: Jeong Chan Ra, D.V.M. Ph.D., Stem Cell Research Center, RNL BIO Co., Ltd, Seoul 153-803, Republic of Korea. Tel: +82-2-858-8021; Fax: +82-2-858-8140; E-mail: jcra@rnl.co.kr

(c) Ivyspring International Publisher. This is an open-access article distributed under the terms of the Creative Commons License (http://creativecommons.org/ licenses/by-nc-nd/3.0/). Reproduction is permitted for personal, noncommercial use, provided that the article is in whole, unmodified, and properly cited.

Received: 2011.01.18; Accepted: 2011.02.25; Published: 2011.03.14

\begin{abstract}
Adipose-derived mesenchymal stem cells (AdMSCs) augment the ability to contribute to microvascular remodeling in vivo and to modulate vascular stability in fresh fat grafts. Although cryopreserved adipose tissue is frequently used for soft tissue augmentation, the viability of the fat graft is poor. The effects of culture-expanded human adipose tissue-derived mesenchymal stem cells (hAdMSCs) on the survival and quality of the cryopreserved fat graft were determined. hAdMSCs from the same donor were mixed with fat tissues cryopreserved at $-70^{\circ} \mathrm{C}$ for 8 weeks and injected subcutaneously into 6-week-old BALB/c-nu nude mice. Graft volume and weight were measured, and histology was evaluated 4 and 15 weeks post-transplantation. The hAdMSC-treated group showed significantly enhanced graft volume and weight. The histological evaluation demonstrated significantly better fat cell integrity compared with the vehicle-treated control 4 weeks post-transplantation. No significant difference in graft weight, volume, or histological parameters was found among the groups 15 weeks post-transplantation. The hAdMSCs enhanced the survival and quality of transplanted cryopreserved fat tissues. Cultured and expanded hAdMSCs have reconstructive capacity in cryopreserved fat grafting by increasing the number of stem cells.
\end{abstract}

Key words: Human adipose tissue-derived mesenchymal stem cells (hAdMSCs), cryopreserved fat tissues, viability of fat grafts, dose-dependent.

\section{Introduction}

Autologous fat transplantation is used for soft tissue augmentation in reconstructing various tissue defects, primarily congenital or acquired facial anomalies, facial rejuvenation, and cosmetic breast augmentation in plastic surgery [1-3]. Although aspirated fat tissue is a safe natural filler with a natural texture, softness, and contour, there are some associated problems, including unpredictability and a low rate of graft survival owing to partial necrosis. Magnetic resonance imaging studies have indicated that the resorption rate in clinical use is $55-70 \%$ of the injected volume [4].

Many clinical methods have been developed to enhance the viability and improve the survival of transplanted fat tissue [2, 3, 5-7]. Tissue-specific progenitor cells in adipose tissue, known as adi- 
pose-derived stem/stromal cells or adipose tissue-derived mesenchymal stem cells (AdMSCs), have the capacity to differentiate into various cell lineages [8] and clinically enhance the viability and effectiveness of fat grafts $[2,3,9]$. To increase the viablity of fat grafts, it is important to minimize the reabsorption rate and to prevent the necrosis of transplanted fat by promoting the growth of new blood vessels [9-13].

The capacity of AdMSCs to secrete multiple bioactive angiogenic and anti-apoptotic growth factors has stimulated interest in the clinical application of these cells. As AdMSCs can be obtained in sufficient numbers in vitro, it may be possible to use cultured AdMSCs to clinically enhance the viability of fat grafts without the need for harvesting cells from a large volume of liposuction aspirate.

In this study, we investigated the effects of human adipose tissue-derived mesenchymal stem cells (hAdMSCs) on the survival of fat grafts in mice. The hAdMSCs were mixed with cryopreserved fat tissue and injected into nude mice. The retained fat weight and volume, and the graft histology were evaluated.

\section{Materials and Methods}

\section{Animals}

Six-week-old male BALB/c-nu nude mice (Orient Bio, Gyonggi-Do, Korea) weighing 13-17 g were used in the experiments. The animals were kept under controlled environmental conditions with constant laminar airflow, temperature of $20-23^{\circ} \mathrm{C}$, and humidity of $40-60 \%$, and a $12 / 12$-h light/dark cycle. They were given access to standard laboratory chow and sterilized water ad libitum.

All experiments were conducted in accordance with the Guide for the Care and Use of Laboratory Animals of Jeju National University.

\section{Preparation of hAdMSCs from aspirated human fat tissues}

Informed consent was obtained for the use of human adipose tissues. Human aspirated fat tissue was obtained by liposuction and was separated from fluids and cell debris by centrifugation. The aspirated fat tissue was frozen directly with liquid nitrogen and stored at $-70^{\circ} \mathrm{C}$ for 8 weeks until used for transplantation experiments.

To prepare hAdMSCs, subcutaneous adipose tissues were digested with $4 \mathrm{~mL}$ of RTase cell isolation enzyme (RNL BIO, Seoul, Korea) per gram of fat under gentle agitation for $60 \mathrm{~min}$ at $37^{\circ} \mathrm{C}$. The digested tissues were filtered through a $100-\mu \mathrm{m}$ nylon sieve to remove cellular debris and were collected by centrifugation at $1500 \mathrm{rpm}$ for $5 \mathrm{~min}$. The pellet was resuspended in RCME cell attachment medium (RNL BIO) containing $10 \%$ fetal bovine serum (FBS). After another centrifugation at $1500 \mathrm{rpm}$ for $5 \mathrm{~min}$, the supernatant was discarded, and the pellet was collected. The cells were cultured overnight at $37^{\circ} \mathrm{C}$ in $5 \% \mathrm{CO}_{2}$ in RCME containing $10 \%$ FBS. Cell adhesion was examined under an inverted microscope $24 \mathrm{~h}$ later. Non-adherent cells were removed after $24 \mathrm{~h}$, the adherent cells were washed with PBS, and the medium was changed to RKCM cell growth medium (RNL BIO) containing 5\% FBS. The cells were maintained for 4-5 days until confluent (passage 0 ) and then expanded in RKCM until passage 3 at $90 \%$ confluence. The immunophenotypes of the AdMSCs were analyzed using a FACSCalibur flow cytometer (BD Biosciences, Franklin Lakes, NJ) and CellQuest software. Every harvest of hAdMSCs revealed a homogenous population of cells with the characteristics of mesenchymal stem cells. The cells expressed mesenchymal stem cell markers, including CD90, CD105, CD44, and CD29, and did not express hematopoietic or endothelial markers (CD31, CD34, and CD45). Cell viability evaluated by trypan blue exclusion before transplantation was greater than $95 \%$. No evidence of bacterial, fungal, or mycoplasmal contamination was observed. The procedure for hAdMSC preparation was performed using good manufacturing practices in the Stem Cell Research Center of RNL BIO (Seoul, Korea).

\section{Fat transplantation}

Fat aspirates and hAdMSCs from the same donor were used in the experiments. A mixture containing $1 \mathrm{~mL}$ of the cryopreserved fat tissue and 300 $\mu \mathrm{L}$ of phosphate-buffered saline (PBS) containing $1 \times 10^{6}(n=6)$ or $1 \times 10^{7}$ hAdMSCs $(n=6)$ was injected subcutaneously over the skulls of the mice. PBS was used as a vehicle control $(n=6)$.

\section{Follow-up and data collection}

The animals were euthanized at 4 or 15 weeks after fat transplantation. No animals died during the study. The remaining grafted fat tissues were dissected out and weighed, and their volumes were determined by the liquid overflow method [7]. Briefly, a graduated cylinder was filled with distilled water, the dissected fat tissues were immersed in the cylinder, and the fat volume was determined by the consequent increase in the water level. Histological evaluations were performed by a professional pathologist in a blinded manner. Each slide was evaluated for the presence of [7, 14]: 1) intact and nucleated fat cells; 2) cysts and vacuoles; 3) inflammation, as evidenced by the infiltration of lymphocytes and macrophages; and 4) fibrosis and other components of connective tissue. Each parameter was graded on a scale from 0 
to 5 as follows: absent, 0 ; minimal presence, 1 ; minimal to moderate presence, 2; moderate presence, 3; moderate to extensive presence, 4 ; and extensive presence, 5 .

\section{Statistical analysis}

The Mann-Whitney rank-sum test was used to compare the fat weight, fat volume, and fat tissue histological parameters among the groups. All statistical analyses were performed using SPSS software (ver. 17.0E; SPSS, Seoul, Korea). For differences between the hAdMSC-treated and control groups, $p$-values less than 0.05 were considered to indicate statistical significance.

\section{Results}

The weight and volume of the remaining grafted fat tissue were determined at 4 and 15 weeks after fat transplantation. Animals were selected at random and sacrificed at each time point (each $n=6)$.
At 4 weeks after transplantation, a significant, dose-dependent increase in the survival of cryopreserved fat grafts was observed in the groups treated with hAdMSCs compared with the vehicle-treated control group (Table 1). There were no significant differences among the groups at 15 weeks after transplantation.

At 4 weeks post-transplantation, histological evaluations of the transplanted fat tissues stained with hematoxylin and eosin revealed significantly better fat cell integrity in the hAdMSC-treated mice compared with vehicle-treated controls $(P<0.05$; Table 2). There were no significant differences in the other histological parameters, including cyst/vacuole formation, inflammation, and fibrosis, among the groups. At 15 weeks post-transplantation, none of the histological parameters differed significantly among the groups (Table 2).

Table I. Comparison of fat graft weight and volume with vehicle and hAdMSCs transplantation.

\begin{tabular}{llllll}
\hline & & \multicolumn{2}{c}{ Fat weight $(\mathrm{g})$} & \multicolumn{2}{c}{ Fat volume $(\mathrm{mL})$} \\
\hline Transplantation & & 4 weeks P.T. & 15 weeks P.T. & 4 weeks P.T. & 15 weeks P.T. \\
\hline Vehicle-control & PBS & $0.13 \pm 0.12$ & $0.22 \pm 0.27$ & $0.18 \pm 0.21$ & $0.22 \pm 0.24$ \\
hAdMSCs & $1 \times 10^{6}$ cells & $0.2 \pm 0.2$ & $0.11 \pm 0.13$ & $0.28 \pm 0.22$ & $0.13 \pm 0.14$ \\
& $1 \times 10^{7}$ cells & $0.5 \pm 0.23^{* \dagger}$ & $0.19 \pm 0.14$ & $0.48 \pm 0.24^{\ddagger}$ & $0.24 \pm 0.14$ \\
\hline
\end{tabular}

Data are expressed as means \pm SD. P.T., post-transplantation

${ }^{*} P<0.05$ vs. vehicle-treated control

$\dagger P<0.05$ vs. treatment with $1 \times 10^{6}$ hAdMSCs

$\neq \mathrm{P}=0.053$ vs. vehicle-treated control

Table 2. Comparison of the histological evaluations with vehicle and hAdMSC transplantation.

\begin{tabular}{|c|c|c|c|c|c|c|c|c|c|}
\hline & & \multicolumn{2}{|c|}{ Integrity $^{a}$} & \multicolumn{2}{|c|}{ Cyst/Vacuolesa } & \multicolumn{2}{|c|}{ Inflammation $^{a}$} & \multicolumn{2}{|c|}{ Fibrosis $^{a}$} \\
\hline Transplantation & & 4 wks P.T. & $\begin{array}{ll}15 & \text { wks } \\
\text { P.T. } & \end{array}$ & 4 wks P.T. & $\begin{array}{ll}15 & \text { wks } \\
\text { P.T. } & \end{array}$ & $\begin{array}{ll}4 & \text { wks } \\
\text { P.T. } & \end{array}$ & $\begin{array}{ll}15 & \text { wks } \\
\text { P.T. } & \end{array}$ & $\begin{array}{l}4 \text { wks } \\
\text { P.T. }\end{array}$ & $\begin{array}{ll}15 & \text { wks } \\
\text { P.T. } & \end{array}$ \\
\hline Vehicle-control & PBS & $3.2 \pm 0.8$ & $2.2 \pm 1.6$ & $1.5 \pm 0.8$ & $1.6 \pm 0.9$ & $1.2 \pm 1.6$ & $2.4 \pm 1.7$ & $1.2 \pm 0.8$ & $1.0 \pm 1.7$ \\
\hline hAdMSCs & $1 \times 10^{6}$ cells & $4.2 \pm 0.4^{*}$ & $2.8 \pm 0.8$ & $1.5 \pm 0.5$ & $1.7 \pm 1.0$ & $0.5 \pm 0.5$ & $2.5 \pm 1.2$ & $0.7 \pm 0.5$ & $2.5 \pm 1.4$ \\
\hline & $1 \times 10^{7}$ cells & $4.5 \pm 0.8^{*}$ & $3.8 \pm 0.4$ & $0.5 \pm 0.5$ & $1.7 \pm 0.5$ & $0.3 \pm 0.5$ & $1.8 \pm 1.5$ & $0.3 \pm 0.5$ & $1.8 \pm 1.2$ \\
\hline
\end{tabular}

Data are expressed as means \pm SD. P.T., post-transplantation

a Scale: 0 , absent; 1 , minimal presence; 2 , minimal to moderate presence; 3 , moderate presence; 4 , moderate to extensive presence; 5 , extensive presence

${ }^{*} P<0.05$ vs. vehicle-treated control 
The dissected fat grafts in the control group were weaker and more fragile than those in the hAdMSC-treated groups at 4 weeks post-transplantation (Fig. 1A-F). In two of the six vehicle-treated controls, the dissected fat graft contained blood-like liquid at 15 weeks post-transplantation (Fig. 2B and 2C). In the other vehicle-treated controls, little of the fat explants remained, and they were composed of connective tissue. At 4 weeks post-transplantation, the fat grafts in the hAdMSC-treated mice $\left(1 \times 10^{6}\right.$ and $1 \times 10^{7}$ cells $)$ were readily dissected and were yellowish (Fig. 1G-R). At 15 weeks post-transplantation, the fat explants were darker yellow in mice treated with $1 \times 10^{6} \mathrm{hAdMSCs}$ (Fig. 2G-L) compared with mice treated with $1 \times 10^{7}$ hAdMSCs (Fig. 2M-R). There were no side effects such as the presence of blood-like liquid in any individual mouse treated with hAdMSCs.

Fat necrosis and fibrosis were observed in the control group at 4 weeks after fat transplantation (Fig.
3A). Despite very mild inflammation and cyst formation in the group treated with $1 \times 10^{6}$ hAdMSCs, the fat grafts in the hAdMSC-treated groups were in better condition than those in the control group (Fig. 3B). Adipocytes showed a homogeneous distribution in the group treated with $1 \times 10^{7} \mathrm{hAdMSCs}$ (Fig. 3C).

Massive fat necrosis and remaining acidophilic ghost-like cells were observed in histological sections of the control group at 15 weeks after fat transplantation. Irregularly sized necrotic fat cells were surrounded by thick progressive fibrosis at 15 weeks post-transplantation (Fig. 3D). Many infiltrating polymorphonuclear cells were present in this fibrotic band. Mild inflammatory cell infiltration and fibrosis were observed in the group treated with $1 \times 10^{6}$ hAdMSCs (Fig. 3E). The distribution of adipocytes was more homogeneous in the mice treated with $1 \times 10^{7}$ hAdMSCs (Fig. 3F) than in those treated with $1 \times 10^{6}$ cells (Fig. 3E). Very mild fibrosis was also seen in the mice treated with hAdMSCs.
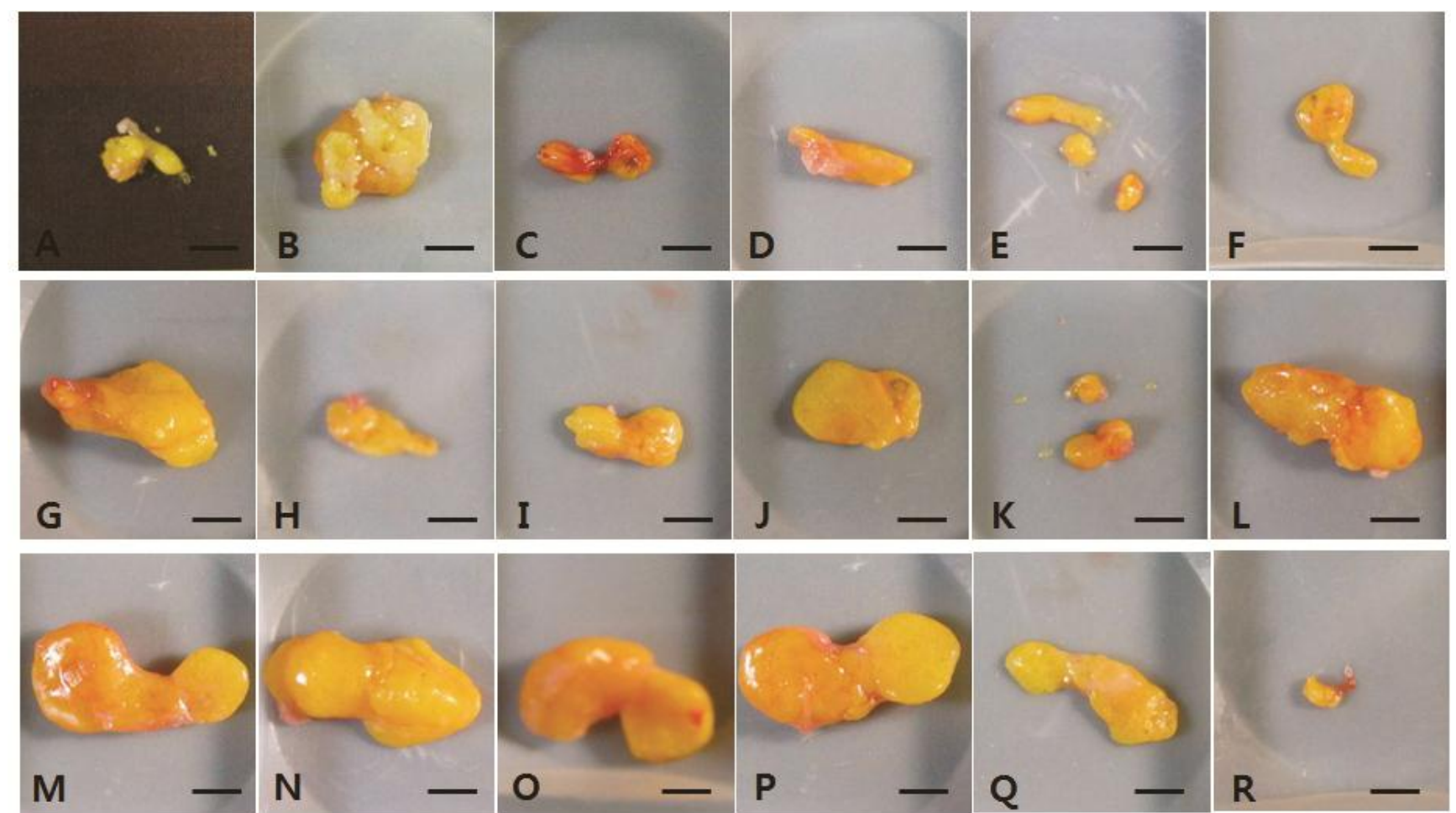

Figure I. The fat explants from individual mice harvested at 4 weeks post-transplantation. A-F, vehicle-treated control group. G-L, I × $10^{6}$ hAdMSC-treated group. M-R, I × $10^{7}$ hAdMSC-treated group. Scale bar $=50 \mathrm{~mm}$. 


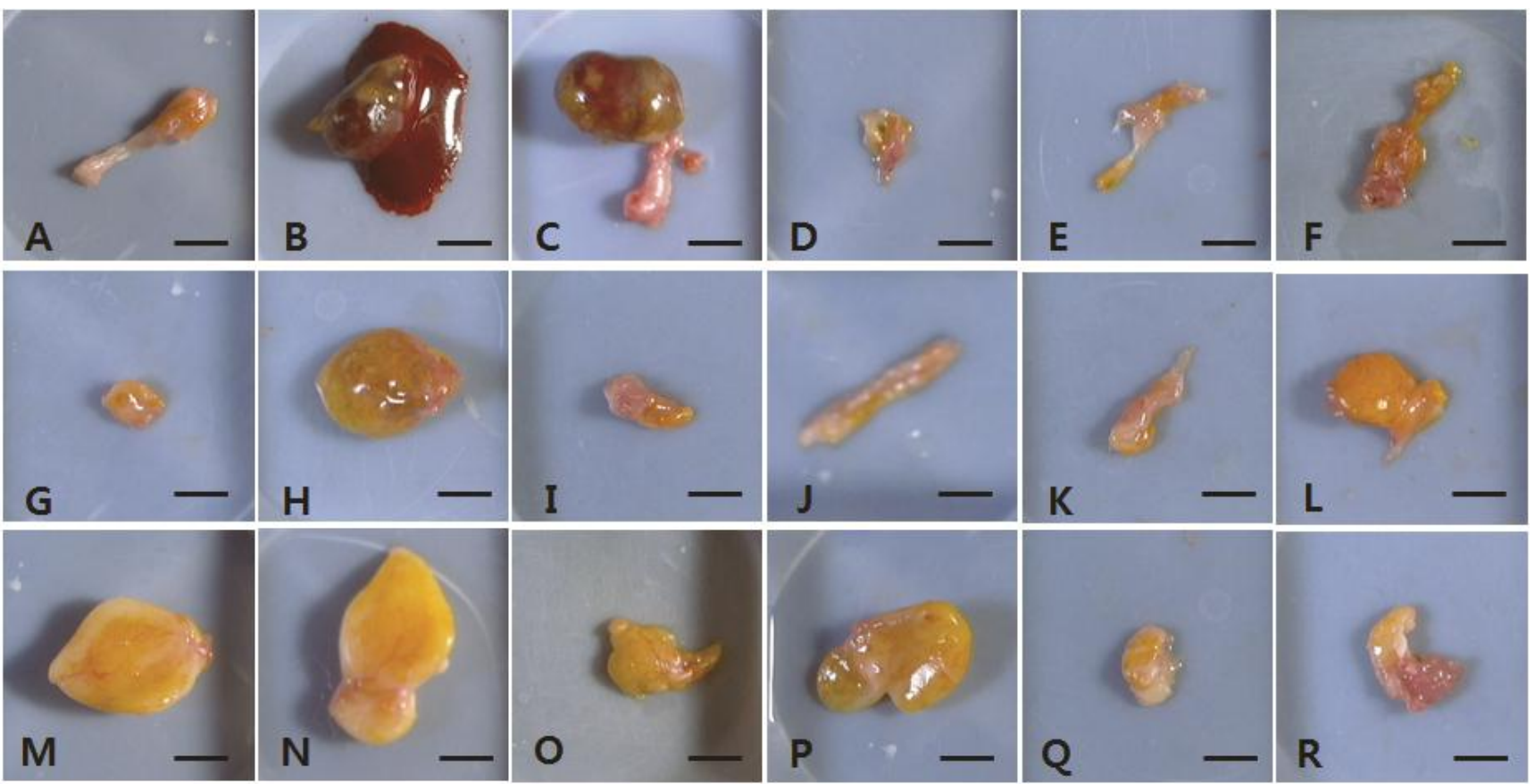

Figure 2. The fat explants from individual mice harvested at 15 weeks post-transplantation. A-F, vehicle-treated control group. G-L, I × $10^{6}$ hAdMSC-treated group. M-R, I × $10^{7}$ hAdMSC-treated group. Scale bar $=50 \mathrm{~mm}$.
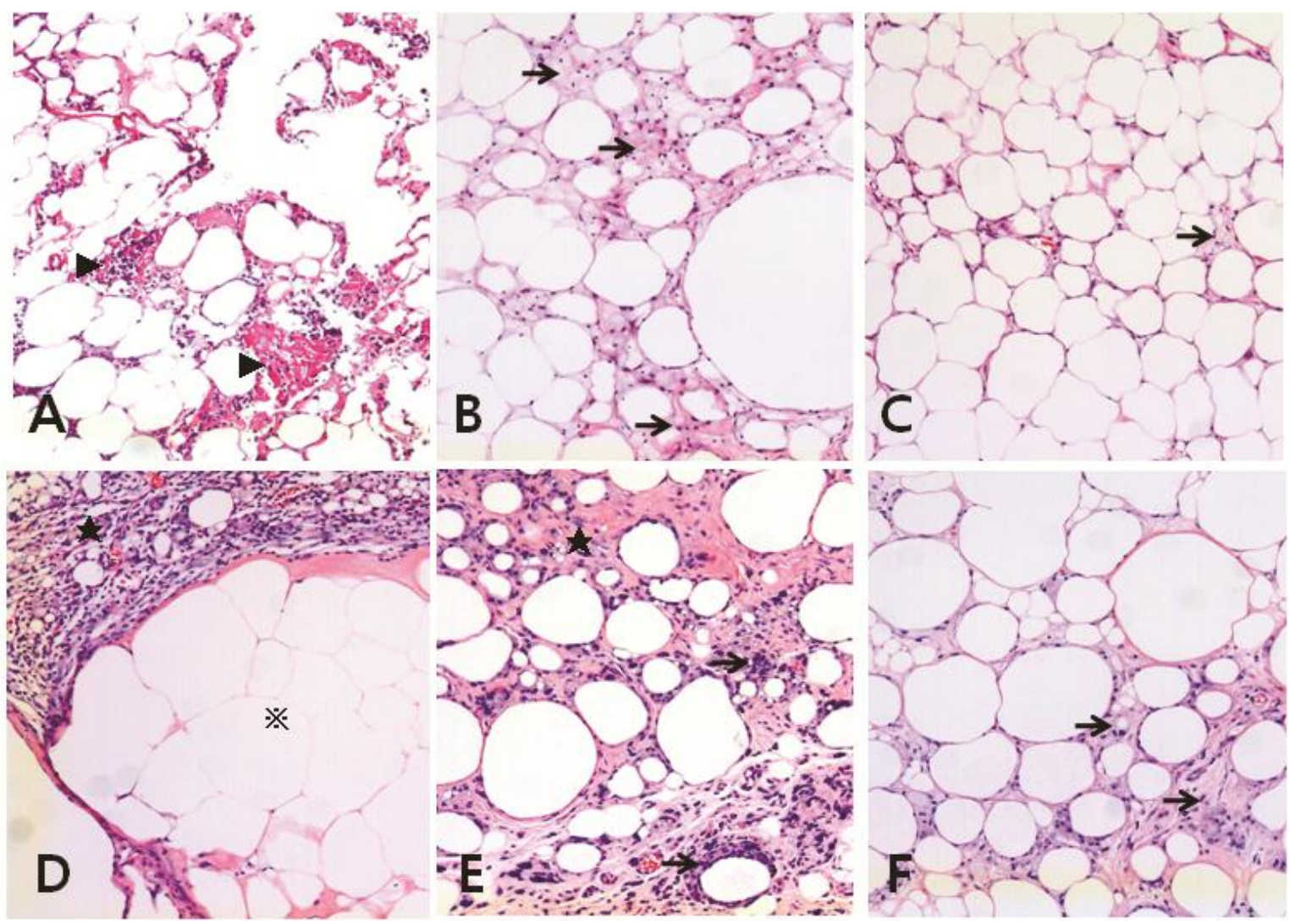

Figure 3. Histological features of fat grafts at $4(A-C)$ and $I 5(D-F)$ weeks post-transplantation (H \& E staining). A and D, vehicle-treated control group. $B$ and $\mathrm{E}, \mathrm{I} \times 10^{6} \mathrm{hAdMSC}$-treated group. $\mathrm{C}$ and $\mathrm{F}, \mathrm{I} \times 10^{7} \mathrm{hAdMSC}$-treated group. All images were taken at 100× magnification. A) Fat necrosis and fibrosis (arrowheads) are seen in the vehicle-treated control group. B) Slight inflammation (arrows) and cyst formation are visible in the $1 \times 10^{6} \mathrm{hAdMSC}$-treated group. C) Slight inflammation 
(arrows) is seen in the $1 \times 10^{7}$ hAdMSCs treated group. D) Irregularly sized necrotic fat cells are surrounded by thick progressive fibrosis (star) at 15 weeks post-transplantation. Many polymorphonuclear cells (PMNs) had infiltrated the fibrotic band. Massive fat necrosis is visible, and acidophilic ghosts remain $(※)$. E) Progressive fibrosis (star) is evident, and some inflammatory cells (arrows) have infiltrated in the $1 \times 10^{6} \mathrm{hAdMSC}$-treated group. F) Slight fibrosis (arrows) is seen in the $1 \times 10^{7}$ hAdMSC-treated group.

\section{Discussion}

Adipose tissue has been used as an autologous, natural filler for soft tissue defects because antigenic and allergic reactions are minimized. Given these advantages, autologous fat transplantation is a useful technique in plastic and reconstructive surgery. Clincally, adipose tissues are taken from the belly or thigh by liposuction as this simple procedure reduces the stress to the patient. However, compared with nonsuctioned adipose tissues, suctioned fat tissues contain fewer multipotent AdMSCs and a majority of impaired adipocytes, because of the centrifugation step used to concentrate and separate adipocytes from the debris, including blood cells, lipids, proteases, and other components [15-19]. The relative deficiency of mutipotent AdMSCs contributes to the unpredictable partial absorption, low survival rate, and long-term atrophy of transplanted lipoaspirates, and repeated lipotransplantation is often necessary $[2,3,18,20]$.

To address these issues, many clinical methods have been tried to enhance the viability and survival rate of transplanted fat tissues [2, 3, 5-7]. Several reports have demonstrated that grafted fat has an increased survival rate when transplanted with the stromal vascular fraction (i.e., AdMSCs) obtained from alternative liposuction aspirates enriched in AdMSCs [2, 3, 18, 20]. This strategy, termed cell-assisted lipotransfer (CAL), has proven to be effective, safe, and superior to conventional lipoinjection used in procedures such as breast reconstruction, cosmetic breast augmentation, and facial lipoatrophy $[2,3]$. However, the efficiency of CAL in terms of survival duration of engrafted fats still shows individual variation.

Another way to increase the efficiency of fat transplantation is repeated fat transplantation with cryopreserved adipose tissues, which avoids repeated surgery to obtain fresh fat tissue. Although adipose tissues cryopreserved under improved conditions gave relatively better results compared with simply cryopreserved fat, the results were still less satisfactory than those with fresh adipose tissues [21, 22].

Accordingly, in this study, we applied cryopreserved aspirated fats and culture-expanded human AdMSCs, because it is difficult to obtain a sufficient number of mesenchymal stem cells from aspirated fat with minimal manipulation. The average number of AdMSCs isolated per gram of aspirated fat without expansion culture is $73,000 \pm 24,700$ cells [12]. In the present study, part of the aspirated fat was processed to culture AdMSCs, and the remaining fat was stored at $-70^{\circ} \mathrm{C}$ until used for transplantation at about 8 weeks. We transplanted human fat tissue over the skulls of nude mice, which have little to no endogenous fat, thereby minimizing the chance of measuring endogenous mouse fat instead of transplanted human fat. Furthermore, the skull has a relatively low blood supply and thus a lower level of fat retention than other sites, including the back, abdomen, and leg muscles, in recipient animals [23].

Our results demonstrated that cultured hAdMSCs improved the quality and viability of implanted adipose tissue, with no central necrosis of the transplanted fat tissue and reduced inflammation and fibrosis. In this study, transplanted fat tissue was frozen directly without any cryoprotectant, which resulted in few or no adipose stem cells in the transplanted fat tissue, because viable adipose stem cells were not harvested from directly frozen adipose aspirates [24]. Our results indicate that expanded AdMSCs provide a reconstructive capacity in aspirated fat grafting by supplementing the number of stem cells. After three or four passages in our culture system, more than one billion cells could be easily obtained from less than $10 \mathrm{~g}$ of fat tissue. The use of cultured AdMSCs can be beneficial when sufficient AdMSCs cannot be obtained via the minimal manipulation of aspirated fat. In addition, because cultured AdMSCs increase the viability of transplanted fat tissues, their use can minimize the amount of fat needed for mammoplasty, which usually requires a large fat graft. Given that there were no differences between the stem cell and control groups at 15 weeks in the present study, additional studies investigating the effects of AdMSCs on the duration of graft survival are needed.

Although the mechanism of action of AdMSCs in a reconstructive capacity was not evaluated here, many previous studies have demonstrated that AdMSCs contribute to increased microvascular density, accelerated neoangiogenesis, and adipocyte differentiation, while preventing apoptosis by producing and releasing soluble angiogenic factors such as vascular endothelial growth factor, hepatocyte growth factor, 
and insulin-like growth factor-1 $[12,13,23]$. The capacity of culture-expanded hAdMSCs [25] and other reported AdMSCs [10, 12, 13, 23] to differentiate into endothelial cells in vitro supports their contribution to neoangiogenesis.

In conclusion, culture-expanded AdMSCs have the capacity to increase fat graft survival and may be beneficial to patients without producing the additional stress associated with obtaining more adipose tissue or performing repeated liposuction.

\section{Conflict of Interest}

The authors have declared that no conflict of interest exists.

\section{References}

1. Coleman SR, Saboeiro AP. Fat grafting to the breast revisited: safety and efficacy. Plast Reconstr Surg 2007;119:775-87.

2. Yoshimura K, Sato K, Aoi N, et al. Cell-assisted lipotransfer for cosmetic breast augmentation: supportive use of adipose-derived stem/stromal cells. Aesthetic Plast Surg 2008;32:48-57.

3. Yoshimura K, Sato K, Aoi N, et al. Cell-assisted lipotransfer for facial lipoatrophy: efficacy of clinical use of adipose-derived stem cells. Dermatol Surg 2008;34:1178-85.

4. Hörl HW, Feller AM, Biemer E. Technique for liposuction fat reimplantation and long-term volume evaluation by magnetic resonance imaging. Ann Plast Surg 1991;26:248-58.

5. Ramon Y, Shoshani O, Peled IJ, et al. Enhancing the take of injected adipose tissue by a simple method for concentrating fat cells. Plast Reconstr Surg 2005;115:197-203.

6. Shoshani O, Shupak A, Ullmann Y, et al. The effect of hyperbaric oxygenation on the viability of human fat injected into nude mice. Plast Reconstr Surg 2000;106:1390-98.

7. Yi C, Pan Y, Zhen Y, et al. Enhancement of viability of fat grafts in nude mice by endothelial progenitor cells. Dermatol Surg 2006;32:1437-43.

8. Zuk PA, Zhu M, Ashjian P, et al. Human adipose tissue is a source of multipotent stem cells. Mol Biol Cell 2002;13:4279-95.

9. Kang JW, Kang KS, Koo HC, et al. Soluble factors-mediated immunomodulatory effects of canine adipose tissue-derived mesenchymal stem cells. Stem Cells Dev 2008;17: 681-93.

10. Amos PJ, Shang H, Bailey AM, et al. IFATS collection: The role of human adipose-derived stromal cells in inflammatory microvascular remodeling and evidence of a perivascular phenotype. Stem Cells 2008; 26:2682-90.

11. Chavakis E, Dimmeler S. Regulation of endothelial cell survival and apoptosis during angiogenesis. Arterioscler Thromb Vasc Biol 2002;22:887-93.

12. Rehman J, Traktuev D, Li J, et al. Secretion of angiogenic and antiapoptotic factors by human adipose stromal cells. Circulation 2004;109:1292-98.

13. Yamaguchi M, Matsumoto F, Bujo $\mathrm{H}$, et al. Revascularization determines volume retention and gene expression by fat grafts in mice. Exp Biol Med (Maywood) 2005;230:742-8.

14. Shoshani O, Livne E, Armoni M, et al. The effect of interleukin-8 on the viability of injected adipose tissue in nude mice. Plast Reconstr Surg 2005;115:853-9.

15. Condé-Green A, Baptista LS, de Amorin NF, et al. Effects of centrifugation on cell composition and viability of aspirated adipose tissue processed for transplantation. Aesthet Surg J 2010;30(2):249-55.
16. Boschert MT, Beckert BW, Puckett CL, Concannon MJ. Analysis of lipocyte viability after liposuction. Plast Reconstr Surg 2002;109:761-5.

17. Galie M, Pignatti M, Scambi I, et al. Comparison of different centrifugation protocols for the best yield of adipose-derived stromal cells from lipoaspirates. Plast Reconstr Surg 2008;122:233e-4e.

18. Matsumoto D, Sato K, Gonda K, et al. Cell-assisted lipotransfer: supportive use of human adipose-derived cells for soft tissue augmentation with lipoinjection. Tissue Eng 2006; 12:3375-82.

19. Suga $H$, Matsumoto $D$, Inoue $K$, et al. Numerical measurement of viable and nonviable adipocytes and other cellular components in aspirated fat tissue. Plast Reconstr Surg 2008;122(1):103-14.

20. Shiffman MA, Mirrafati S. Fat transfer techniques: the effect of harvest and transfer methods on adipocyte viability and review of the literature. Dermatol Surg 2001;27:819-26.

21. Pu LL, Cui X, Li J, et al. The fate of cryopreserved adipose aspirates after in vivo transportation. Aesth Surg J 2006;26(6):653-61.

22. Shoshani O, Ullmann Y, Shupak A, et al. The role of frozen storage in preserving adipose tissue obtained by suction-assisted lipectomy for repeated fat injection procedures. Dermatol Surg 2001;27(7):645-7.

23. Zhu M, Zhou Z, Chen Y, et al. Supplementation of fat grafts with adipose-derived regenerative cells improves long-term graft retention. Ann Plast Surg 2010;64(2):222-8.

24. Lee JE, Kim I, Kim M. Adipogenic differentiation of human adipose tissue- derived stem cells obtained from cryopreserved adipose aspirates. Dermatol Surg 2010;36(7):1078-83.

25. Ra JC. Safety of passaged human adipose tissue-derived mesenchymal stem cell and its ability of neovascularization in an animal model for hindlimb ischemic disease; A Thesis For the Degree of Doctor of Veterinary Medicine. Korea: Jeju National University. 2008.

\section{Author Biography}

Dr. Jeong Chan Ra, DVM, PhD is the founder, CEO and Chairman of RNL BIO, a leading biopharmaceutical company dedicated to the development of adult stem cell therapeutics. He has worked to develop stem cell therapeutics for autoimmune, degenerative and many other incurable diseases through standardization of therapeutic methods using autologous adipose tissue derived and placenta derived mesenchymal stem cells. Dr. Ra established the technology for isolating, expanding and preserving mesenchymal stem cell from small amount of abdominal subcutaneous fat tissue. He also proved the safety of adipose tissue derived mesenchymal stem cells that were intravenously administered in animal and human. Dr. Ra has registered and issued patents related stem cells including a patent "Multipotent stem cells derived from human adipose tissue and cellular therapeutic agents comprising the same" in Korea, United State of America and Russia. Based on this technology, RNL BIO has completed the Phase I clinical study for the treatment of Spinal Cord Injury using adipose tissue derived stem cells isolated and expanded at a GMP standard. Another two studies are under progress in Phase I/IIa for treatment of Osteo- 
arthritis and Buerger's disease. In collaboration with various teams from universities or medical institutes, clinical studies are conducted to identify the efficacy of mesenchymal stem cells in many obstinate ailments such as Alzheimer disease, Myocarcial infarction, Diabetes Mellitus, Autoimmune diseases or Amyotrophic Lateral Sclerosis. Dr. Ra has recently published his book, "Thank you! Stem Cell", which explains the definition, utilization, research trend and effectiveness of stem cell in plain words and has already become a best seller in Korea and translated into four languages. He has also published over 10 stem cell related research articles in leading scientific journals. 